\title{
Avaliação do estado nutricional de indivíduos adultos sadios de classe média. Ingestão energética e protéica, antropometria, exames bioquímicos do sangue e testes de imunocompetência*
}

\author{
Assessment of nutritional status of healthy middle class young and adult sub- \\ jects living in Botucatu, State of S. Paulo, Brazil. Energy and protein intakes, \\ anthropometric and blood biochemical estimations and immunocompetence \\ tests
}

\author{
Marco Aurélio de Carvaiho Anselmo"* , Roberto Carlos Burini ${ }^{* *}$, Aparecida Yooko Outa Angeleli ${ }^{\star * \star}$, \\ Norma Gerusa da Silva Mota 'Álvaro Oscar Campana
}

\begin{abstract}
ANSELMO, M.A. de C. et al. Avaliação do estado nutricional de indivíduos adultos sadios de classe média. Ingestão energética e protéica, antropometria, exames biequímicos do sangue e testes de imunocompetência. Rev. Saúde públ., S. Paulo, 26: 46 - 53, 1992 Foram estudados parâmetros relacionados ao estado nutricional de 151 adultos sadios, pertencentes à classe média e residindo em. Botucatu, SP, Brasil. Valores antropométricos foram maiores nos homens, com exceção da prega tricipital e da área adiposa do braço. O aumento da idade associou-se a aumento dos valores da massa muscular (homens e mulheres) e do peso do corpo, da prega tricipital e da área adiposa do braço (mulheres). Os resultados antropométricos aproximaram-se dos valores referenciais internacionais, mas não foram inteiramente concordantes com eles, sendo inferiores para o peso corpóreo e circunferência e área musculares do braço. Nos indivíduos de menos de 50 anos, os valores da ingestão energética foram ligeiramente inferiores aos níveis recomendados. $A$ ingestão protéica foi adequada. Os valores médios das proteínas e lípides do soro foram similares aos valores de referência. Testes de hipersensibilidade cutânea são apresentados como uma prova funcional para avaliação do estado nutricional.
\end{abstract}

Descritores: Estado nutricional. Antropometria. Inquéritos nutricionais

\section{Introdução}

No Brasil, alguns estudos sobre avaliação do estado nutricional basearam-se em amostras populacionais amplas, tais como ${ }_{26}$ realizado nos Estados do. Nordeste, em $1963^{26}$; o "Estudo Nacional da Despesa Familiar - ENDEF", desenvolvido em 1974 e $1975^{13}$; a investigação levada a efeito em Santo André, em crianças e jovens até 19 anos de idade $^{21}$ e o "Perfil de Crescimento da População Brasileira de 0 a 25 anos", de 1989 do "Plano Nacional sobre Saúde e Nutrição (PNSN, 1989) ${ }^{\prime \prime}{ }^{17}$

No que concerne a indivíduos adultos, há investigações relacionadas a grupos populacionais

* Subvencionado pela Fundação de Amparo à Pesquisa do Estado de São Paulo (FAPESP) - Processo Medicina 81/0350-9. Apresentado parcialmente no XIII International Congress of Nutrition, Brighton, UK, 1985.

* Departamento de Clínica Médica da Faculdade de Medicina de Botucatu da Universidade Estadual Paulista Botucatu, SP - Brasil.

*** Departamento de Microbiologia e Imunologia do Instituto de Biociências de Botucatu da Universidade Estadual Paulista - Botucatu, SP - Brasil.

Separatas/Reprints: A.O. Campana - 18610 - Botucatu, SP Brasil.

Publicação financiada pela FAPESP. Processo Saúde Coletiva 91/4994-0. menores. Assim, foram obtidos dados sobre ingestão alimentar, antropométricos e bioquímicos a partir de grupos populacionais definidos como "bóias frias" trias", estudantes universitários ${ }^{1,16}$ e habitantes da cidade de Vitória, Espirito Santo ${ }^{6}$. Os dados disponíveis mostraram a existência de diferenças entre os valores de algumas variáveis estudadas, como a ingestão energética, o peso corpóreo e a estatura. As diferenças observadas podem, em parte, ser atribuídas a fatores associados às características das diferentes regiōes do Brasil ${ }^{18,33}$. A par das diferenças regionais, as de uma mesma região parecem estar associadas às diferenças de nível socioeconômico das amostras estudadas ${ }^{17,18,33}$.

Atualmente não dispomos de padrões para peso, estatura e outros parâmetros antropométricos que possam ser considerados demonstrativos da população brasileira adulta. Os dados recentemente publicados pelo PNSN, referentes à população adulta, são preliminares e não incluem a população de mais de 25 anos de idade ${ }^{17}$. Desta maneira, estudos locais, envolvendo grupos populacionais menores e definidos, são úteis para o estabelecimento de valores de referência regionais e para comparação com outros grupos de caracteristicas simila- 
res. Estas razões motivaram a realização do presente trabalho, que foi centrado em um grupo definido e relativamente homogêneo de pessoas sadias da classe média de cidade do interior do Estado de São Paulo. Seus objetivos foram: a) estabelecer valores para variáveis relacionadas com a avaliação do estado nutricional; b) verificar a influência do sexo e da idade sobre os valores das variáveis estudadas; c) verificar a aderência dos valores obtidos com os valores referenciais internacionais.

A observação de que crianças desnutridas apresentam maior número de infecções e infeç̧ōes mais graves, desenvolveu o interesse por estudos sobre o relacionamento entre desnutrição e comprometimento da imunocompetência. Evidenciada a associação entre deficiências nutricionais e diminuição da imunocompetência, testes relacionados a esta passaram a ser recomendados e usados como indicadores funcionais do estado nutricional ${ }^{4,5,30}$.

Desta maneira, no presente trabalho, foram utilizados para a avaliação do estado nutricional, os seguintes métodos: antropometria, ingestão alimentar, exames bioquímicos do sangue e reações cutâneas de hipersensibilidade.

\section{Casuística e Método}

Delineamento $e$ casuística - Os participantes voluntários do estudo foram submetidos a exame clínico e laboratoriais de rotina com a finalidade de se excluírem afecções orgânicas e perturbações nutricionais. Os indivíduos considerados sadios do ponto de vista clínico-laboratorial passavam à fase seguinte, onde eram avaliados sob o ponto de vista antropométrico, dietético, bioquímico e imunitário.

Desta maneira, foram estudados 151 indivíduos sadios, radicados ou que moravam na cidade de Botucatu, no Estado de São Paulo. Tratava-se de um grupo homogêneo do ponto de vista socioeconômico, composto de pessoas pertencentes à classe média: alunos universitários, docentes, funcionários do Campus de Botucatu e seus parentes idosos. Para o estabelecimento do número de indivíduos a ser estudado em cada sexo, levaram-se em conta dados prévios e as estatísticas correspondentes aos parâmetros estudados; a partir da maior variabilidade, que foi o da trigliceridemia, chegouse ao " $n$ " amostral de 70. Foram estudadas 78 pessoas do sexo masculino e 73, do feminino. Para o estudo do efeito da idade sobre as variáveis estudadas, os indivíduos foram distribuídos em três faixas etárias: de 18 a 29 anos, compreendendo in-

Tabela de Composição de Alimentos da Disciplina de Nutrição do Departamento de Clínica Médica da Faculdade de Medicina de Ribeirāo Preto - USP, 1976. Dados inéditos. divíduos jovens; de 30 a 49 anos, correspondendo aos adultos em fase de maturidade e a faixa de mais de 50 anos.

Métodos - a) Ingestão energética e protéica Foi utilizado o método recordatório de $24 \mathrm{~h}$, repetido três vezes por semana, às segundas, quartas e quintas-feiras, por entrevistadores, visando à coleta de dados relacionados ao consumo alimentar. Os dados obtidos foram convertidos para peso e transformados em número de calorias e de gramas de proteínas por dia, usando-se tabela de conversão de alimentos ${ }^{*}$. O consumo de álcool foi também registrado, junto com outras bebidas.

b) Antropometria - Mediram-se estatura e peso do corpo. O índice de massa do corpo, ou índice de Quételet, foi estimado a partir do peso do corpo e da estatura, conforme a relação peso $(\mathrm{em} \mathrm{kg}) /$ estatura (em metros) ao quadrado.

A espessura das pregas cutâneas (pregas tricipital e subescapular) foi medida com paquímetro apropriado (Lange Skinfold Caliper - Cambridge Scientific Industries - U.S.A.), de acordo com o procedimento usado por Bishop e col. ${ }^{3}$. A circunferência braquial foi medida com auxílio de fita milimetrada apropriada. A circunferência muscular do braço, a área braquial, a área muscular do braço e a área adiposa do braço foram calculadas a partir da circunferência braquial e da prega tricipital, de acordo com Frisancho ${ }^{11,12}$.

c) Exames laboratoriais - Os exames laboratoriais foram realizados pela manhã, após período de repouso e jejum de 8 a 10 horas. A concentração das proteínas totais do soro foi determinada pelo método do biureto, adaptado ao analisador automático ABBA $100^{28}$; a concentração da albumina, pelo método do verde de bromocresol ${ }^{8}$; de lípides totais, pela reação da sulfofosfovanilina ${ }^{24}$; de triglicérides, pelo método de Soloni ${ }^{24}$ modificado, utilizando-se "kit" da Labtest Sistemas Diagnósticos Ltda. e de colesterol, pela técnica da reação de Liebermann Burchard, de acordo com Huang e col. ${ }^{15}$.

A contagem diferencial de leucócitos foi feita em sangue colhido por punção digital. A enumeração de tipos de linfócitos (linfócitos T: timo-dependentes e linfócitos B: bursa-dependentes) foi feita de acordo com o método de Mendes e col. ${ }^{23}$, em sangue venoso.

d) Reações de hipersensibilidade tardia - Os testes foram realizados em 58 indivíduos. A hipersensibilidade tardia foi analisada com três antígenos: Candidina, PPD e Vaccinia (Alergofar, Brasil); observou-se, também, a reação à fitohemoaglutinina (PHA para uso clínico, Wellcome Reagents, England). A face anterior do antebraço direito foi utilizada para a realização das reações intradérmicas, de acordo com o procedimento adotado por Mota ${ }^{25}$. As leituras foram realizadas após 
$24 \mathrm{~h}$ (fitohemoaglutinina) e $48 \mathrm{~h}$ (antígenos heterólogos). A área de enduração foi medida $\mathrm{em} \mathrm{mi-}$ límetros, calculando-se a média aritmética de seus dois maiores diâmetros.

e) Tratamento estatístico - Calcularam-se os valores médios e os desvios padrões para cada uma das variáveis estudadas. Para a comparação entre os grupos (de acordo com sexo e idade), foi utilizada a análise de variância para experimento inteiramente casualizado, determinando-se o efeito do sexo, da idade e da interação sexo $\mathrm{x}$ idade. Foi verificado o efeito do sexo dentro de cada idade e o efeito da idade dentro de cada sexo. Os contrastes entre médias foram feitos pelo método de Tukey.

Quanto às reações de hipersensibilidade cutânea, foi apresentada a frequiência das reaçōes positivas; as diferenças entre os grupos etários foram estabelecidas pelo teste do quiquadrado e, entre os sexos, pelo texte de Fisher.

O nivel de significância adotado foi de $5 \%$.

\section{Resultados}

Avaliação antropométrica - Na Tabela 1 estão registrados o valor médio e o desvio padrão para cada uma das variáveis estudadas em 144 indivíduos. Influéncia do sexo: para os mesmos grupos etários, os valores médios de estatura, peso do corpo, circunferência muscular do braço e área muscular do braço são maiores nos homens do que nas mulheres. Nos homens, observam-se valores menores da prega tricipital nos três grupos etários e da área adiposa do braço nos dois grupos de mais idade (30-49 anos e 50-79 anos). A prega subescapular não foi medida nos grupos mais jovens; nos grupos de mais idade, as diferenças observadas entre os sexos não são significantes. Nos grupos etários de 18 a 29 anos, o índice de Quételet é mais alto nos homens do que nas mulheres, mas nos grupos de mais idade, os valores do índice não são diferentes entre os sexos. Influência da idade: Nos homens, os valores da estatura são maiores, e os da circunferência muscular do braço e área muscular do braço são menores no grupo mais jovem do que nos dois grupos de mais idade; nestes dois últimos grupos, as diferenças entre as médias correspondentes às variáveis citadas não são significantes. Comparação de médias não revelou efeito significante da idade quanto aos seguintes parâmetros: peso do corpo, indice de Quételet, prega tricipital, prega subescapular (para indivíduos de mais de 30 anos), circunferência do braço e área adiposa do braço. Quanto às mulheres, os valores médios de todas as variáveis (com exceção da estatura e da prega subescapular) são menores no grupo mais jovem do que nos dois grupos de mais idade (30-49 anos e 50-69 anos); nestes últimos grupos, as diferenças observadas não são significantes. Valores da prega subescapular não variam com a idade (para pessoas de mais de 30 anos); o mesmo ocorre com a estatura (nas três faixas etárias).

Tabela 1. Características antropométricas (valores médios \pm SD) de individuos sadios: alunos, docentes e funcionários da Universidade e seus parentes idosos, por sexo e idade - Botucatu, Estado de São Paulo.

\begin{tabular}{|c|c|c|c|c|c|c|c|}
\hline & \multirow{3}{*}{$\begin{array}{l}\text { Idade } \\
\text { (anos) }\end{array}$} & \multicolumn{3}{|c|}{ Homens } & \multicolumn{3}{|c|}{ Mulheres } \\
\hline & & $18-29$ & 30.49 & 50.79 & $18-29$ & 30.49 & 50.69 \\
\hline & & $n=31$ & $n=24$ & $n=19$ & $n=33$ & $n=23$ & $n=14$ \\
\hline Estatura $(\mathrm{cm})$ & & $175,8 \pm 6,0^{\mathrm{a}}$ & $172,0 \pm 5,8^{b}$ & $171,0 \pm 5,7^{b}$ & $159,6 \pm 5,0^{\circ}$ & $157,8 \pm 7,7^{6}$ & $159,4 \pm 5,1^{c}$ \\
\hline Peso do corpo (kg) & & $72,3 \pm 10,0^{6}$ & $73,9 \pm 10,8^{a}$ & $73,5 \pm 10,4^{a}$ & $54,6 \pm 6,9^{b}$ & $62,1 \pm 9,4^{c}$ & $64,1 \pm 10,0^{c}$ \\
\hline $\begin{array}{l}\text { Índice de massa do } \\
\text { corpo }\left(\mathrm{kg} / \mathrm{m}^{2}\right)\end{array}$ & & $23,3 \pm 2,4^{a}$ & $25,0 \pm 3,2^{a}$ & $25,1 \pm 2,9^{a}$ & $21,4 \pm 2,2^{b}$ & $25.0 \pm 3,8^{a}$ & $25,2 \pm 3,6^{a}$ \\
\hline $\begin{array}{l}\text { Prega cutânea tricipital } \\
(\mathrm{mm})\end{array}$ & & $15,2 \pm 6,9^{a}$ & $12,8 \pm 5,1^{a}$ & $12,4 \pm 3,4^{a}$ & $19,4 \pm 4,5^{b}$ & $24,9 \pm 7,8^{c}$ & $25,1 \pm 9,3^{c}$ \\
\hline $\begin{array}{l}\text { Prega cutânea } \\
\text { subescapular }(\mathrm{mm})\end{array}$ & & . & $20,0 \pm 8,2^{a}$ & $17,8 \pm 6,5^{\mathrm{a}}$ & . & $\begin{array}{l}22,7 \pm 10,9^{a} \\
(22)^{a}\end{array}$ & $22,9 \pm 8,7^{\mathrm{a}}$ \\
\hline $\begin{array}{l}\text { Circunferência do } \\
\text { braço }(\mathrm{mm})\end{array}$ & & $297 \pm 25,2^{\mathrm{a}}$ & $303 \pm 29,4^{a}$ & $302 \pm 27,1^{\mathrm{a}}$ & $263 \pm 23,6^{b}$ & $297 \pm 32,4^{a}$ & $301 \pm 34,0^{a}$ \\
\hline $\begin{array}{l}\text { Circunferência } \\
\text { muscular do braço } \\
\text { (mm) }\end{array}$ & & $249 \pm 16,5^{\mathrm{a}}$ & $263 \pm 22,2^{b}$ & $263 \pm 24,4^{b}$ & $202 \pm 19,2^{b}$ & $219 \pm 20,4^{\circ}$ & $222 \pm 23,3^{c}$ \\
\hline Área do braço $\left(\mathrm{mm}^{2}\right)$ & & $7051 \pm 1223^{a}$ & $7378 \pm 1462^{a}$ & $7323 \pm 1294^{a}$ & $5547 \pm 994^{\mathrm{b}}$ & $7108 \pm 1567^{a}$ & $7278 \pm 1694^{a}$ \\
\hline $\begin{array}{l}\text { Área muscular do } \\
\text { braço }\left(\mathrm{mm}^{2}\right)\end{array}$ & & $4944 \pm 645^{8}$ & $5539 \pm 929^{b}$ & $5564 \pm 1024^{b}$ & $3281 \pm 635 b$ & $3850 \pm 719^{c}$ & $3958 \pm 815^{\circ}$ \\
\hline $\begin{array}{l}\text { Área adiposa do braşo } \\
\left(\mathrm{mm}^{2}\right)\end{array}$ & & $2108 \pm 1034^{a}$ & $1839 \pm 861^{\mathrm{a}}$ & $1759 \pm 554^{\mathrm{a}}$ & $2266 \pm 606^{\mathrm{a}}$ & $3258 \pm 1238^{b}$ & $3321 \pm 1409^{b}$ \\
\hline
\end{tabular}

* Número em parênteses corresponde ao número de individuos examinados.

Resultados estatisticos:

1) Em cada sexo, para comparação de faixas etárias: letras diferentes indicam diferenças significantes: $P<0,05$;

ii) Em cada faixa etária, para comparaçāo dos sexos: letras diferentes indicam diferenças significantes: $P<0,05$ 
Avaliação da ingestão energética e protéica A Tabela 2 apresenta os valores médios e os desvios padrões da ingestão de energia e de proteínas de 144 indivíduos entrevistados. Influéncia do sexo: nos mesmo grupos etários, a ingestäo de energia e de proteínas é maior nos homens de 18 a 29 anos e de 30 a 49 anos de idade; nos grupos de mais de 50 anos, a diferença entre sexos não é significativa. Contudo, quando a ingestão é expressa como $\mathrm{kcal} / \mathrm{kg}$ de peso do corpo (energia) e $\mathrm{g} / \mathrm{kg}$ de peso do corpo (proteínas), as diferenças entre sexos deixam de ser significativas nos três grupos etários. Isto implica que a ingestão mais elevada, observada nos homens de 18 a 49 anos, deve-se ao seu peso corpóreo, que é maior do que aquele das mulheres. Influência da idade: nos homens, a ingestão energética (expressa como $\mathrm{kcal} / \mathrm{dia}$ ou $\mathrm{kcal} / \mathrm{kg}$ de peso corpóreo) não apresenta variações significantes de acordo com a idade. A ingestão protéica, em g/dia, é maior no grupo mais jovem em relação ao mais velho, mas não em relação ao grupo de idade intermediária; não há diferença significante entre os valores da ingestão protéica (em g/dia) entre os dois grupos de mais idade. Quando a ingestão protéica é expressa em $\mathrm{g} / \mathrm{kg}$ de peso do corpo, verifica-se que ela é maior para o grupo mais jovem; não há diferença de ingestão entre os dois grupos de mais idade. Quanto às mulheres, não foram observadas diferenças de ingestão energética e protéica de acordo com a idade.

Avaliação laboratorial - Na Tabela 3, estão registrados o valor médio e o desvio padrão para cada uma das variáveis estudadas, em 150 indi- víduos. Influência do sexo: diferenças significantes foram apenas verificadas quanto aos niveis de triglicérides que, em cada grupo etário, são mais elevados nos homens; as outras variáveis não apresentam variações significantes relacionadas ao sexo: proteínas totais, albumina, globulinas, lípides e colesterol do soro e número de linfócitos totais, T e B. Influência da idade: diferenças significantes verificam-se quanto aos linfócitos T e B: o número de linfócitos $\mathrm{T}$ é menor no grupo de mulheres de 30 a 49 anos, na comparação com o grupo mais jovem; por sua vez, o número de linfócitos $\mathrm{B}$ é menor, nos homens, nos dois grupos de mais idade e, nas mulheres, no grupo de 30 a 49 anos, quando comparado ao grupo mais jovem.

Avaliação imunitária - Na Tabela 4, está registrado o número de indivíduos com reações positivas aos testes cutâneos de hipersensibilidade. Verificaram-se: a) menor freqüência de positividade da reação à Candidina nas mulheres de 30 a 49 anos, que nos homens de mesma idade; b) frequiência baixa de reatividade ao PPD nos grupos de homens e mulheres mais jovens (de 18 a 29 anos de idade); e c) todos os indivíduos testados com fitohemoglutinina reagiram positivamente.

Entre os 58 indivíduos examinados quanto aos testes de hipersensibilidade, 32 foram submetidos aos quatro testes: 11 apresentaram reação positiva aos quatro antígenos, 10 a três antígenos e 11 a dois antígenos. Assim, este grupo de individuos sadios apresentou duas reações positivas, pelo menos, quando submetido aos quatro testes empregados.

Tabela 2. Ingestảo energética e protéica (valores médios \pm SD) de indivíduos sadios: alunos, docentes e funcionários da Universidade e seus parentes idosos, por sexo e idade - Botucatu, Estado de Sảo Paulo

\begin{tabular}{|c|c|c|c|c|c|c|c|}
\hline & \multirow[b]{2}{*}{$\begin{array}{l}\text { Idade } \\
\text { (anos) }\end{array}$} & \multicolumn{3}{|c|}{ Homens } & \multicolumn{3}{|c|}{ Mulheres } \\
\hline & & $\begin{array}{c}18-29 \\
n=30\end{array}$ & $\begin{array}{c}30=49 \\
n=24\end{array}$ & $\begin{array}{c}50 \cdot 79 \\
n=18\end{array}$ & $\begin{array}{c}18 \cdot 29 \\
n=28\end{array}$ & $\begin{array}{c}30 \cdot 49 \\
n=23\end{array}$ & $\begin{array}{c}50 \cdot 69 \\
n=12\end{array}$ \\
\hline $\begin{array}{l}\text { Ingeståo energética } \\
\text { kcal/dia }\end{array}$ & & $2396 \pm 527^{a}$ & $\begin{array}{c}2540 \pm 548^{a} \\
(23)^{\star}\end{array}$ & $\begin{array}{c}2511 \pm 511^{a} \\
(17)^{\star}\end{array}$ & $1846 \pm 626^{b}$ & $1881 \pm 618^{b}$ & $2313 \pm 604^{\star *}$ \\
\hline $\mathrm{kcal} / \mathrm{kg}$ peso do corpo & & $\begin{array}{c}33,5 \pm 7,3^{a} \\
(29)^{*}\end{array}$ & $35,2 \pm 9,4^{a}$ & $35,1 \pm 9,2^{a}$ & $35,4 \pm 1,2^{8}$ & $30,5 \pm 9,9^{a}$ & $34,6 \pm 7,7^{a}$ \\
\hline Ingestão protéica g/dia & & $114 \pm 40^{a}$ & $\begin{array}{l}97 \pm 32^{\star \star \star *} \\
(23)^{\star}\end{array}$ & $\begin{array}{c}88 \pm 26^{b} \\
(17)^{*}\end{array}$ & $73 \pm 26^{c}$ & $78 \pm 26^{c}$ & $77 \pm 29 * *$ \\
\hline $\mathrm{g} / \mathrm{kg}$ peso do corpo & & $\begin{array}{c}1,6 \pm 0,5^{a} \\
(29)^{ \pm} \\
\end{array}$ & $1,3 \pm 0,5^{b}$ & $1,3 \pm 0,4^{6}$ & $1,4 \pm 0,6^{a}$ & $1,3 \pm 0,4^{\star \star * \star *}$ & $1,1 \pm 0,3^{* * * *}$ \\
\hline
\end{tabular}

\footnotetext{
" Números em parênteses correspondem aos números de indivíduos.

Resultados estatisticos: I) Em cada sexo, para comparaçáo de faixas otárias: Letras diferentes indicam diferenças significantes: $P<0,05$;

II) Em cada faixa etária, para comparaçào dos sexos: Letras diferentes indicam deferenças significantes: $P<0,05$.

* Este valor não é deferente dos observados nos grupos de mulheres mais jovens e do valor dos homens de mesma idade.

*** Nāo há diferença entre este valor e os observados nos grupos de homens mais jovens e de mais idade. **** Estes valores nāo são diferentes entre si e do valor observado no grupo de mulheres mais jovens; também não são diferentes dos valores dos homens de mesma idade.
} 
Tabela 3. Valores de constituintes bioquímicos do soro e de linfócitos do sangue (valores Médjos $\pm S D$ ) de individuos sadios: alunos, docentes e funcionários da Universidade e seus parentes idosos, por sexo e idade - Botucatu, Est. de Sảo Paulo.

\begin{tabular}{|c|c|c|c|c|c|c|c|}
\hline & \multirow{3}{*}{$\begin{array}{l}\text { Idade } \\
\text { (Anos) }\end{array}$} & \multicolumn{3}{|c|}{ Homens } & \multicolumn{3}{|c|}{ Mulheres } \\
\hline & & $18-29$ & $30 \cdot 49$ & $50 \cdot 79$ & $18 \cdot 29$ & $30 \cdot 49$ & $50 \cdot 69$ \\
\hline & & $n=33$ & $n=24$ & $n=20$ & $n=35$ & $n=24$ & $n=14$ \\
\hline Proteinas totais $(g / d \mid)$ & & $7,1 \pm 0,5^{a}$ & $7,4 \pm 0,5^{a}$ & $7,1 \pm 0,7^{a}$ & $7,1 \pm 0,3^{a}$ & $7,3 \pm 0,5^{a}$ & $7,1 \pm 0,7^{a}$ \\
\hline Albumina $(g / d l)$ & & $4,5 \pm 0,5^{a}$ & $4,6 \pm 0,5^{a}$ & $4,4 \pm 0,4^{a}$ & $4,4 \pm 0,4^{a}$ & $4,5 \pm 0,4^{a}$ & $4,3 \pm 0,2^{a}$ \\
\hline Globulinas totais $(g / d l)$ & & $2,5 \pm 0,7^{a}$ & $2,8 \pm 0,5^{\mathrm{a}}$ & $2,8 \pm 0,6^{a}$ & $2,7 \pm 0,6^{a}$ & $2,8 \pm 0,3^{a}$ & $2,8 \pm 0,6^{a}$ \\
\hline Lipides totais (mg/dl) & & $571 \pm 143^{a}$ & $677 \pm 200^{a}$ & $672 \pm 221^{a}$ & $568 \pm 128^{a}$ & $615 \pm 120^{a}$ & $636 \pm 185^{a}$ \\
\hline Triglicérides (mg/dl) & & $125 \pm 87^{a}$ & $164 \pm 91^{a}$ & $128 \pm 78^{a}$ & $84 \pm 38^{b}$ & $98 \pm 36^{b}$ & $123 \pm 49^{b}$ \\
\hline Colesterol total $(\mathrm{mg} / \mathrm{dl})$ & & $195 \pm 29^{a}$ & $214 \pm 46^{a}$ & $191 \pm 29^{a}$ & $189 \pm 34^{a}$ & $194 \pm 41^{a}$ & $200 \pm 56^{a}$ \\
\hline $\begin{array}{l}\text { Linfócitos totais } \\
\text { (células } / \mathrm{mm}^{3} \text { ) }\end{array}$ & & $2243 \pm 718^{\mathrm{a}}$ & $2165 \pm 659^{a}$ & $2141 \pm 898^{a}$ & $2211 \pm 724^{a}$ & $1966 \pm 676^{\mathrm{a}}$ & $2235 \pm 734^{a}$ \\
\hline $\begin{array}{l}\text { Linfócitos } \mathrm{T} \\
\text { (células } / \mathrm{mm}^{3} \text { ) }\end{array}$ & & $1100 \pm 362^{2}$ & $\begin{array}{c}1056 \pm 386^{a} \\
(22)^{*}\end{array}$ & $\begin{array}{c}808 \pm 267^{a} \\
(11)^{*}\end{array}$ & $1163 \pm 464^{a}$ & $\begin{array}{c}846 \pm 299^{* *} \\
(23)^{*}\end{array}$ & $\begin{array}{c}885 \pm 204^{a} \\
(6)^{\star}\end{array}$ \\
\hline $\begin{array}{l}\text { Linfócitos } B^{3} \\
\text { (células } / \mathrm{mm}^{3} \text { ) }\end{array}$ & & $511 \pm 222^{a}$ & $\begin{array}{c}360 \pm 100^{b} \\
(21)^{*}\end{array}$ & $\begin{array}{c}284 \pm 102^{b} \\
(11)^{*}\end{array}$ & $492 \pm 171^{a}$ & $\begin{array}{c}342 \pm 150^{* *} \\
(22)^{*}\end{array}$ & $\begin{array}{c}353 \pm 165^{a} \\
(6)^{*}\end{array}$ \\
\hline
\end{tabular}

Tabela 4. Resposta aos testes cutâneos de hipersensibilidade retardada em individuos sadios: alunos, docentes e funcionários da universidade e seus parentes idosos, por sexo e idade - Botucatu, Estado de Såo Paulo.

\begin{tabular}{|c|c|c|c|c|c|c|c|}
\hline \multirow[b]{3}{*}{ Antigenos } & \multirow[b]{3}{*}{$\begin{array}{l}\text { Idade } \\
\text { (anos) }\end{array}$} & \multicolumn{6}{|c|}{ Número de casos com teste positivo } \\
\hline & & \multicolumn{3}{|c|}{ Homens } & \multicolumn{3}{|c|}{ Mulheres } \\
\hline & & $\begin{array}{c}18 \cdot 29 \\
n=11\end{array}$ & $\begin{array}{c}30 \cdot 49 \\
n=12\end{array}$ & $\begin{array}{c}50-79 \\
n=9\end{array}$ & $\begin{array}{c}18-29 \\
n=8\end{array}$ & $\begin{array}{c}30=49 \\
n=10\end{array}$ & $\begin{array}{c}50 \cdot 69 \\
n=8\end{array}$ \\
\hline Fitohematoagutinina & & $11^{a}$ & $\begin{array}{c}9 a \\
(9)^{*}\end{array}$ & - & $8^{a}$ & $\begin{array}{l}4 a \\
(4)\end{array}$ & - \\
\hline PPD & & $2^{a}$ & $11^{b}$ & $6^{b}$ & $3^{a}$ & $9^{b}$ & $6^{b}$ \\
\hline Candidina & & $8^{a}$ & $12^{a}$ & $4^{a}$ & $6^{a}$ & $4^{* *}$ & $3^{a}$ \\
\hline Vaccinia & & $6^{\mathrm{a}}$ & $10^{a}$ & $5^{a}$ & $7^{\mathrm{a}}$ & $6^{\mathrm{a}}$ & $7^{a}$ \\
\hline
\end{tabular}

* Números em parênteses correspondem aos números de idivíduos examinados.

Resultados estatísticos: 1) Em cada sexo, para comparação de faixas etárias: letra diferentes indicam deferenças significantes: $P<0,05$;

II) Em cada faixa etária, para comparaçào dos sexos: letras diferentes indicam deferenças significantes: $P<0,05$.

* Este valor não é diferente dos observados nos dois outros grupos de mulheres e é diferente do valor dos homens de mesma idade.

\section{Discussão}

Peso do corpo, estatura e as variáveis relacionadas à massa muscular (circunferência muscular do braço-CMB e área muscular do braço-AMB) apresentam valores maiores nos homens do que nas mulheres, nos três grupos etários estudados (Tabela 1). Diferentemente, valores da prega tricipital, indice relacionado à gordura do corpo ${ }^{14}$, são sempre maiores nas mulheres (Tabela 1).
Os dados da presente pesquisa, mostraram, também, um possível efeito da idade em algumas variáveis. Nos homens, há aumento das variáveis relacionadas à massa muscular (CMB e $\mathrm{AMB})$ no grupo de 30 a 49 anos, em relação ao grupo mais jovem (Tabela 1). Nas mulheres, o aumento da idade acompanha-se de aumento do peso do corpo, das variáveis relacionadas à massa muscular (CMB e $\mathrm{AMB})$ e de índices relacionados à gordura (prega tricipital e área adiposa do braço) (Tabela 
1). Efeito similar da idade sobre valores dos parâmetros relacionados à massa muscular, em homens e mulheres, e sobre a prega tricipital, em mulheres, foi observado em estudos feitos nos Estados Unidos da América do Norte ${ }^{3,12}$. O aumento dos valores da prega tricipital e da área adiposa do braço pode ser explicado pelo aumento do teor de gordura do corpo sob a influência da idade ${ }^{20}$; esta deposição de gordura, nas mulheres, além de se efetuar centralmente, também ocorre perifericamen$\mathrm{te}^{20}$, como nos membros superiores.

$O$ aumento dos valores da circunferência e da área muscular do braço (CMB e AMB) sob influência da idade, em homens, pode, em parte, ser atribuído ao aumento da massa muscular, porque os dados disponíveis na literatura indicam que a massa magra do corpo alcança um valor máximo, entre 30 a 40 anos $^{20}$. Esta interpretação é cabível, porque o aumento ocorreu no grupo de 30 a 49 anos, em relação ao grupo de homens mais jovens.

No presente trabalho, valores médios de peso do corpo, estatura e prega tricipital são geralmente maiores do que os observados em outros estudos brasileiros $6,7,9,13,26,36$. Estas diferenças podem, em parte, tanto ser atribuídas a diferenças regionais como ao nível socioeconômico dos grupos estudados.

É de interesse examinar como nossos resultados se comportam em relação aos valores internacionais de referência habitualmente utilizados para a avaliação do estado nutricional ${ }^{3,12,29}$. Na presente amostra registram-se valores menores para estatura, peso do corpo, circunferência muscular do braço e, nos homens, também para a área muscular do braço. As diferenças são pequenas quanto à estatura (até $3 \%$ ) e maiores quanto ao peso do corpo (até $10 \%$ ), à circunferência muscular do braço (3 a 9\%) e, nos homens, à área muscular do braço (9 a 16\%). Quanto aos valores da prega tricipital e da área adiposa do braço, nossos valores são iguais ou maiores que os referenciais usualmente utilizados ${ }^{3,12}$.

Vários fatores podem estar envolvidos para explicar as diferenças mencionadas, como genéticos, características da alimentação e condições de vida e de saúde. No presente trabalho verificamos que os valores médios da ingestão energética (em $\mathrm{kcal} / \mathrm{kg}$ de peso do corpo) revelaram-se, nos grupos etários de 18 a 29 anos e de 30 a 49 anos, inferiores aos recomendados para adultos exercendo atividade física de leve a moderada ${ }^{27,32}$ (Tabela 2). Em conseqüência, os valores menores do peso do corpo poderiam ser considerados decorrentes da menor ingestão energética. Quanto aos valores menores dos parâmetros relacionados com a massa muscular (CMB e AMB), eles poderiam corresponder à diminuição da massa magra do corpo, que também acompanha a adaptação biológica à diminuição da ingestão alimentar ${ }^{34}$. As ressalvas a esta interpretação relacionam-se ao método utilizado para a obtenção dos valores da ingestão alimentar, isto é, o método recordatório ${ }^{22,31}$. Contudo, este método é considerado capaz de fornecer estimativas razoáveis da ingestão alimentar média de grupos de indivíduos, comparáveis às técnicas mais trabalhosas ${ }^{2}$. Acresce que os presentes resultados sobre ingestão energética, no grupo etário de 18 a 29 anos, são superponíveis aos de um grupo de estudantes universitários de idade semelhante, estudado em Ribeirão Preto ${ }^{16}$.

Os valores médios relativos à ingestão protéica encontram-se acima dos níveis recomendados pela WHO/FAO/UNU ${ }^{19}$ e também acima dos níveis recomendados para a dieta mista brasileira ${ }^{32}$ (Tabela 2). Em concordância com a adequação do aporte protéico, os níveis de concentração sérica de proteínas totais e de albumina, na presente amostra, estão dentro dos padrões de referência ${ }^{35}$ (Tabela 3). Os demais resultados de exames bioquímicos do soro também estão dentro dos intervalos de referência internacionalmente aceitos ${ }^{35}$ (Tabela 3).

Atualmente, o estudo imunitário faz parte do conjunto de métodos usados para avaliação do estado nutricional ${ }^{4}$. Têm sido principalmente utilizadas a contagem de linfócitos e as provas de hipersensibilidade cutânea. Com relação aos testes de hipersensibilidade, os resultados do presente trabalho indicam que indivíduos sadios podem não apresentar reação a um ou outro antígeno entre aqueles usualmente empregados para estudo da imunidade (Tabela 4). Em consequüência, é de interesse para a avaliação correta da hipersensibilidade tardia, que as respostas a vários antígenos sejam examinadas. No presente trabalho foi utilizada uma bateria constando de quatro antígenos. Finalmente, note-se o valor da fitohematoaglutinina para a avaliação da imunocompetência, pois todos os indivíduos testados apresentaram reação positiva a este estimulador direto de linfócitos.

Em conclusão, o grupo estudado de indivíduos sadios, pertencentes à classe média, apresentou valores antropométricos próximos, mas não iguais aos dos padrões internacionais (com exceção da prega tricipital e da área adiposa do braço). As diferenças referem-se, principalmente, ao peso do corpo e aos parâmetros relacionados à massa muscular, cujos valores são menores. A ingestão energética (em $\mathrm{kcal} / \mathrm{kg}$ de peso do corpo), medida pelo método recordatório, encontra-se abaixo das recomendações preconizadas, nos grupos de menos de 50 anos de idade; isto pode representar um dos fatores relacionados às diferenças mencionadas quanto ao peso do corpo e à massa muscular. $\mathrm{Na}$ amostra, a ingestão protéica e os exames bioquimicos de sangue estão de acordo, respectivamente, com a recomendação e os padrões referenciais aceitos. $O$ estudo também mostra que pessoas sa- 
dias podem não reagir a um ou outro antígeno relacionado á hipersensibilidade cutânea; desta maneira, para o estudo imunitário, aconselha-se o uso de bateria de testes.

\section{Agradecimentos}

À Prof. ${ }^{a}$ Sheila Zambello de Pinho e ao Prof. Paulo Roberto Curi pelo auxílio na análise estatística; às biólogas Maria Rita de C. Mathias e Edna Correa Cervi pela assistência técnica.

ANSELMO, M.A. de C. et al. [Assessment of nutritional status of healthy middle class young and adult subjects living in Botucatu, State of S. Paulo Brazil. Energy and protein intakes, anthropometric and blood biochemical estimations and immunocompetence tests]. Rev. Saúde públ., S. Paulo, 26: 46 - 53, 1992. Nutritional status was assessed in 151 middle-class healthy adult individuals (69 medical students, $18-29$ y, 34 males, 35 females); 48 university personnel, 30-49 y, 24 males, 24 females; and their older relatives, 34 subjects, $50-79$ y, 19 males, 15 females) living in Botucatu, S. Paulo. Methods included anthropometric measurements, energy and protein intakes, blood biochemical analyses and cutaneous delayed hypersensitivity tests. Anthropometric measurements showed higher values in men, with the exception of the triceps skifold thickness (higher in women) and of the arm fat area (higher in the older age female groups); aging seemed to be associated with increases of weight, arm muscle variables and with arm fat accumulation in women and with increases of arm muscle variables in men. The values for anthropometric measurements were in general higher than those found in other Brazilian studies; on the other hand, they approximate to but do not entirely agree with the data representative of the international referential adult population: differences were mainly concerned with body weight and upper arm muscle parameters, which were lower in our sample. As regards energy intake, values found in subjects under 50 years of age were lower than the recommended dietary allowances; averages found for protein intake were above the level recommended by WHO/FAO/UNU (1985). The mean values for serum proteins and lipids were similar to those of referential data. As regards the hypersensitivity tests, it was found that none of the individuals challenged with four antigens (PPD, Candidin, Vaccinia and phytohemagglutinin) presented less than two positive skin reactions. Besides, all the subjects challenged with phytohemagglutinin had positive reaction to this direct lymphocyte stimulator.

Keywords: Nutritional status. Anthropometry. Nutrition surveys.

\section{Referências Bibliográficas}

1. ANSELMO, M.A. de C.; BURINI, R.C.; CAMPANA, A.O. Food intake and anthropometric assessment of healthy medical students, university personal staff and their older relatives. In: Intemational Congress of Nutrition, 13, Brighton, U.K., 1985. The book of abstracts. Brighton, 1985. p.192.

2. BEATON, G.H.; MILNER, J.; COREY, P.; McGUIRE, V.; COUSINS, M.; STEWART, E.; DE RAMOS, M.; HEWITT, D.; GRAMBSCH, P.V.; KASSIM, N.; LITTLE, J.A. Sources of variance in 24-hour dietary recall data: implications for nutrition study design and interpretation. Amer. J. clin. Nutr., 32: 2546-59, 1979.

3. BISHOP, C.W.; BOWEN, P.E.; RITCHEY, S.J. Norms for nutritional assessment of American adults by upper arm anthropometry. Amer. J. clin. Nutr., 34: 2530-9, 1981.

4. BLACKBURN, G.L.; BELL, S.J.; MULLEN, J.L. Nutritional medicine: a case management approach. Philadelphia, W.B. Saunders Co., 1989.

5. CHANDRA, R.K. \& SCRIMSHAW, N.S. Immunocompetence in nutritional assessment. Amer. J. clin. Nutr., 33: 2694-7, 1980.

6. COSTA, O.L.; SANTOS, D.M.; NÉSPOLI, C.A.; CENTODUCATTE, F.; SOUZA, E.F.; LIMA, E.G.; FAINTUCH, J. Padrôes de normalidade para medidas antropométricas: estudo sistemático em uma população adulta brasileira. Rev. Hosp. Clin. Fac. Med. S. Paulo, 42: 49-54, 1987.

7. DESAI, I.D.; GARCIA TAVARES, M.L.; DUTRA DE OLIVEIRA, B.S.; DOUGLAS, A.; DUARTE, F.A.M.; DUTRA DE OLIVEIRA, J.E. Food habits and nutritional status of agricultural migrant workers in Southern Brazil. Amer. J. clin. Nutr., 33: 702-14, 1980.

8. DOUMAS, B.T.; WATSON, W.A.; BIGGS, H.G.; Albumin standards and the measurement of serum albumin with bromocresol green. Clin. chim. Acta, 31: 87-96, 1971.

9. FAINTUCH, J.; PEREIRA, M.L.; FAINTUCH, B.L.; MACHADO, M.C.C.; PINOTTI, H.W. Novos parâmetros para avaliação nutricional; investigação preliminar. Rev. Hosp. Clin. Fac. Med. S. Paulo, 38: 164-6, 1983.

10. FREDERICO, N.T.; MARCHDNI, J.S.; DUTRA DE OLVEIRA, J.E. Alimentação e avaliação do estado nutricional de trabalhadores migrantes safristas na região de Ribeirão Preto, SP (Brasil). Rev. Saúde públ., S. Paulo, 18: 375-81, 1984.

11. FRISANCHO, A.R. Triceps skinfold and upper arm muscle size norms for assessment of nutritional status. Amer. J. clin. Nutr., 27: 1052-8, 1974.

12. FRISANCHO, A.R. New norms of upper limb fat and muscle areas for assessment of nutritional status. Amer. J. clin. Nutr., 34: 2540-5, 1981.

13. FUNDAÇĀO IBGE: Estudo nacional da despesa familiar. Rio de Janeiro, 1977. v.1, t.1, p.1-4.

14. GARROW, J.S. Indices of adiposity. Nutr. Abst. Rev. Ser. A., 53: 697-708, 1983.

15. HUANG, T.C.; CHEN, C.P.; WEFLER, V.; RAFTERY, A. A stable reagent for the Liebermann-Burchard reaction. Application to rapid serum cholesterol determination. Anal. Chem., 33: 1405-7, 1961.

16. INFANTE. S.; JOSALA, E.; SHYOIA, E.S.; MARCHINI, J.S.; VANNUCHI, H.; DUTRA DE OLIVEIRA, J.E; UNAMUNO, M.R.D.L; VEIGA, E.V.; NAVES, M.M.V.; IPPOLLITTI, R.G. Estado nutricional de estudantes universitários do Campus de Ribeirão Preto da Universidade de São Paulo. 
Cienc. Cult., 34 (Supl.): 803, 1982.

17. INSTITUTO NACIONAL DE ALIMENTAÇÃO E NUTRIÇÃO (INAN). Perfil de crescimento da população brasileira de 0 a 25 anos; pesquisa nacional sobre saúde e nutriçāo. Brasília, Ministério da Saúde, 1990.

18. JANSEN, G.R.; JANSEN, N.B.; SHIGETOMI, C.T.; HARPER, J.M. Effect of income and geographic region on the nutritional value of diets in Brazil. Amer. J. clin. Nutr., 30: 955-64, 1977.

19. JOINT FAO/WHO/UNU EXPERT CONSULTATION ON ENERGY AND PROTEIN REQUIREMENTS, Roma, 1981. Report. Geneva, World Health Organization, 1985. (WHO Techinal. Reports. Series, 724).

20. KUCZMARSKI, R. Need for body composition information in elderly subjects. Amer. $J$. clin. Nutr., 50 (Suppl.): 1150-7, 1989.

21. MARCONDES, E. Normas para a diagnóstico e a classificação dos distúrbios do crescimento e da nutrição: última versão. Pediatria, S. Paulo, 4: 307-26, 1982.

22. MEDLIN, C. \& SKINNER, J.D. Individual dietary intake methodology: a 50-year review of progress. J. Amer. diet. Ass., 88: 1250-7, 1988.

23. MENDES, N.F.; TOLNEI, M.E.A.; SILVEIRA, N.P.A.; GILBERTSEN, R.B.; METZGAR, R.S. Technical aspects of rosette tests used to detect human complement receptor (B) and sheep erythrocyte binding (T) lymphocytes. J. Immunol., 111: 860-7, 1973.

24. MOURA, R.A. de A. Técnicas de laboratório. 2a. ed. Rio de Janeiro, Livraria Atheneu Ltda, 1982.

25. MOTA, N.G.S. Comportamento de provas cutâneas para avaliação da imunidade celular em pacientes com hanseniase virchoviana. Botucatu, 1973. [Tese de Doutorado - Faculdade de Ciências Médicas e Biológicas de Botucatu].

26. NORTHEAST BRAZIL: NUTRITION SURVEY, March-May 1963; report by the Interdepartmental Committee on Nutrition for National Development. Washington, D.C., 1965.
27. PELLETT, P.L. Food energy requirements in humans. Amer. J. clin. Nutr., 51: 711-22, 1990.

28. SKEGGS Jr., L.T. \& HOCHSTRASSER, H. Multiple automatic sequential analyses. Clin. Chem., 10: 918-36, 1964.

29. SIMOPOULOS, A.P. Characteristics of obesity: an overview. In: Wurtman, R.J. \& Wurtman, J.J., eds. Human obesity. New York, The New York Academy of Sciences, 1987. p. 4.

30. SOLOMONS, N.W. \& ALLEN, L.H. The functional assessment of nutritional status: principles, practice and potential. Nutr. Rev., 41: 33-50, 1983.

31. STOCKLEY, L. Assessment of long-term intake. In: Taylor, T.G. \& Jenkings, N.K., eds. Proceedings of the XIII International Congress of Nutrition, 1985. London, John Libbey \& Co., 1986. p. 710.

32. VANNUCCHI, H.; MENEZES, E.W.; CAMPANA, A.O.; LAJOLO, F.M. Aplicação das recomendações nutricionais à populaçẫo brasileira. Ribeirão Preto, Editora Legis Suma Ltda, 1990.

33. VIACAVA, F; FIGUEIREDO, C.M.P. de; OLIVEIRA, W.A. A desnutrição no Brasil: uma análise do Estudo Nacional da Despesa Familiar (IBGE 74/75) para o Nordeste, Estado de São Paulo e Estado do Rio de Janeiro. Petrópolis, Editora Vozes Ltda/ Financiadora de Estudos e Projetos (FINEP), 1983.

34. WATERLOW, J.C. Observations on the FAO's methodology for estimating the incidence of undernutrition. Food Nutr. Bull., 11: 8-13, 1989.

35. YOUNG, D.S. Implementation of SI units for clinical laboratory data. Ann. intern. Med, 106: 114-29, 1987.

36. ZUÑIGA, H.P.P.; SIQUEIRA, L.A.; CARTAGENA, H.A. Estado nutricional e posse de terra: um estudo em adultos da área rural do Nordeste Brasileiro. Arch. latinoamer. Nutr., 36: 67-78, 1986.

Recebido para publicação em 12/7/1991 Aprovado para publicaçāo em 21/11/1991 